\title{
Differentially Methylated Loci Distinguish Ovarian Carcinoma Histological Types: Evaluation of a DNA Methylation Assay in FFPE Tissue
}

\author{
Linda E. Kelemen, ${ }^{1,2}$ Martin Köbel, ${ }^{3,4}$ Angela Chan, ${ }^{5}$ Soreh Taghaddos, ${ }^{6}$ and Irina Dinu ${ }^{6}$ \\ ${ }^{1}$ Department of Population Health Research, Alberta Health Services-Cancer Care, Calgary, AB, Canada T2S 3C3 \\ ${ }^{2}$ Departments of Medical Genetics and Oncology, University of Calgary, Calgary, AB, Canada T2N 4N2 \\ ${ }^{3}$ Department of Pathology and Laboratory Medicine, Calgary Laboratory Services, Calgary, AB, Canada T2N 2T9 \\ ${ }^{4}$ Department of Pathology and Laboratory Medicine, University of Calgary, Calgary, AB, Canada T2N 4N2 \\ ${ }^{5}$ Department of Molecular Pathology, Tom Baker Cancer Centre, Alberta Health Services, Calgary, AB, Canada T2N 4N2 \\ ${ }^{6}$ Department of Public Health Sciences, University of Alberta, Edmonton, AB, Canada T6G 1C9
}

Correspondence should be addressed to Linda E. Kelemen; lkelemen@post.harvard.edu

Received 4 July 2013; Accepted 19 August 2013

Academic Editor: John P. Geisler

Copyright ( 2013 Linda E. Kelemen et al. This is an open access article distributed under the Creative Commons Attribution License, which permits unrestricted use, distribution, and reproduction in any medium, provided the original work is properly cited.

\begin{abstract}
Epigenomic markers can identify tumor subtypes, but few platforms can accommodate formalin-fixed paraffin-embedded (FFPE) tumor tissue. We tested different amounts of bisulfite-converted (bs) DNA from six FFPE ovarian carcinomas (OC) of serous, endometrioid, and clear cell histologies and two HapMap constitutional genomes to evaluate the performance of the GoldenGate methylation assay. Methylation status at each 1,505 CpG site was expressed as $\beta$-values. Comparing $400 \mathrm{ng}$ versus $250 \mathrm{ng}$ bsDNA, reproducibility of the assay ranged from Spearman $r^{2}=0.41$ to 0.90 , indicating that $\beta$-values obtained with a lower DNA amount did not always correlate well with the higher amount. Average methylation for the six samples was higher using $250 \mathrm{ng}$ ( $\beta$-value $=$ $0.45, \mathrm{SD}=0.29)$ than with $400 \mathrm{ng}(\beta$-value $=0.36, \mathrm{SD}=0.32)$. Reproducibility between duplicate HapMap samples $\left(r^{2}=0.76\right.$ to 0.92 ) was also variable. Using $400 \mathrm{ng}$ input bsDNA, THBS2 and $E R G$ were differentially methylated across all histologic types and between endometrioid and clear cell types at $<0.1 \%$ false discovery rate. Methylation did not always correlate with gene expression $\left(r^{2}=-0.70\right.$ to 0.15$)$. We found that lower bsDNA overestimates methylation, and, using higher bsDNA amounts, we confirmed a previous report of higher methylation of THBS2 in clear cell OC, which could provide new insight into biological pathways that distinguish OC histological types.
\end{abstract}

\section{Introduction}

Epigenetics is defined as heritable changes in gene expression that are not accompanied by changes in the DNA sequence itself [1]. These changes are critical for key eukaryotic processes of development and differentiation and may help to explain the mechanism by which one tissue is distinguished from another developmentally [2]. Physiologically, these processes include control of gene expression [1], X chromosomal inactivation [3], maintenance of chromatin structure [4], and genomic imprinting [5].

The best understood example of epigenetic modification is DNA methylation, which is well-associated with transcriptional repression [1]. DNA methylation occurs on the $\mathrm{C} 5$ position of cytosines that precede guanines (CpG dinucleotides) and at non-CpG cytosines in plants and embryonic stem cells in mammals $[6,7]$. CpG dinucleotides are unequally distributed across the human genome and can exist as CpG islands (CGIs), defined as sequences approximately $1 \mathrm{~kb}$ in length with an elevated $\mathrm{G}+\mathrm{C}$ content of $>50 \%$ and observed frequency $>0.60$ [8]. While most CpGrich repetitive DNA sequences and heterochromatin are normally methylated [9], CGIs within the $5^{\prime}$ promoter regions of genes are normally unmethylated, allowing active gene transcription. Pathologically, aberrant silencing or expression leads to diseases such as cancer [1]. It has been shown that 
differentially methylated regions that are associated with normal tissue differentiation overlap considerably with regions where methylation changes occur in cancers [10], supporting the "epigenetic progenitor model of cancer," which states that methylation changes that drive normal cell development and differentiation are the main mechanism by which epigenetic changes drive cancer [10-12].

Carcinomas classified as ovarian are the fourth most common among female cancers [13], and one of the most complex of all human malignancies [14]. Five major histologic types exist (high-grade serous, endometrioid, clear cell, mucinous, and low-grade serous) [15]. Efforts to understand these carcinomas have focused on clinical and pathological observations [16] and, more recently, on molecular mechanisms of tumor development [17-19]. Most of our knowledge of the methylation in ovarian tumors is based on studies that predate genome-wide approaches. Methylated loci in candidate genes have been evaluated, but studies did not always stratify by histology (reviewed in [20]). Among the moststudied high-grade serous ovarian carcinomas, methylation of BRCA1 is a consistent finding [21-26]: $10-18 \%$ of women show gene silencing due to promoter methylation, whereas $B R C A 2$ promoter methylation is rare [21, 22, 27-29]. DNA methylation at specific loci in ovarian cancers, as in other cancers, is nonrandom, tumor-specific, and reproducibly measured [30].

High-throughput technologic advances permit the simultaneous evaluation of thousands of CpG loci across the human genome, but few platforms exist that accommodate archival formalin-fixed paraffin-embedded (FFPE) tumor tissue. The Illumina GoldenGate Cancer Panel I methylation assay targets $1,505 \mathrm{CpG}$ sites across 808 growth- and development-related genes known to be differentially methylated in various carcinomas and has been tested for application in FFPE samples [31-34]. Concern with the assay performance using the manufacturer's minimum input DNA, however, motivated the current investigation to evaluate assay reproducibility using different quantities of input DNA from six FFPE primary ovarian carcinomas of high-grade serous, endometrioid, and clear cell histologies and two constitutional genomes from the HapMap Project [35]. A secondary objective was to identify and confirm previously reported ovarian histology-specific methylation markers [36].

\section{Methods}

2.1. Patients. Patients were sampled from an ongoing study of ovarian histological types comprising approximately 1,000 women with ovarian carcinomas (300 endometrioid, 300 clear cell, 300 mucinous, and 100 high-grade serous). Women were identified from the Alberta Cancer Registry, a population-based registry that records and maintains data on all new cancer cases and cancer deaths occurring in the province of Alberta, Canada, and for whom we are collecting detailed pathologic assessment, tumor tissue, and clinical data from medical chart abstraction. In 2010, we retrieved hematoxylin and eosin-stained slides and corresponding FFPE tumor blocks for eight patients (four high-grade serous, two endometrioid, and two clear cell ovarian carcinomas) diagnosed with primary incident ovarian carcinoma in 2005. Two patients with high-grade serous carcinoma were excluded: one due to block unavailability and the other from insufficient extracted tumor DNA at the time of assay. A diagnostic gynecological pathologist $(\mathrm{MK})$ reviewed slides, confirmed histology and identified malignant regions corresponding to $>70 \%$ tumor cell nuclei. The protocol was approved by the University of Calgary Conjoint Health Research Ethics Board.

\subsection{DNA Extraction, Bisulfite Conversion, and bsDNA Quan-} titation. Sections of $10 \mu \mathrm{m}$ thickness were cut from each of the six FFPE tumor blocks to achieve sufficient input DNA for comparing the performance of the Illumina GoldenGate Cancer Panel I methylation assay at two different DNA amounts: 250 ng sodium bisulfite-converted (bs) DNA (Illumina manufacturer's minimum recommendation) [31-33] and $400 \mathrm{ng}$ bsDNA. FFPE sections were treated with xylene to remove the paraffin, followed by DNA extraction using the DNeasy Blood and Tissue kit (Qiagen, Germantown, Maryland, USA) according to the manufacturer's instruction. DNA concentration was quantitated using the Biophotometer (Eppendorf, Westbury, NY, USA). Each $10 \mu \mathrm{m}$ section produced $\sim 1 \mu \mathrm{g}$ extracted DNA from each patient. In order to obtain sufficient quantities of bsDNA for the Illumina GoldenGate methylation assay, six to eight reactions of $1 \mu \mathrm{g}$ DNA were subjected to bisulfite treatment using the EZ DNA Methylation-Gold kit (Zymo Research, Orange, CA, USA) according to the manufacturer's instruction. Bisulfiteconverted DNA was quantitated using the Quant-iT OliGreen ssDNA kit (Invitrogen, Paisley, UK) following the manufacturer's guidelines. According to this protocol, $\sim 2 \mu \mathrm{g}$ extracted DNA per patient produced 100-200 ng bsDNA. All reagents were recommended by Illumina, Inc., for FFPEextracted DNA to achieve robust results [32].

2.3. Quality Control. Duplicate samples for each of two laboratory controls were plated on the same chip using the manufacturer recommended amount of $250 \mathrm{ng}$ bsDNA to evaluate the reproducibility of the assay. We used a blood-based source of DNA from two unrelated individuals, NA10851 male and NA10859 female of Northern or Western European ancestry obtained from the Centre d'Etude du Polymorphisme Humain (CEPH) population in the HapMap project (Coriell, Camden, NJ, USA), according to a previously published protocol [33]. We hypothesized that $250 \mathrm{ng}$ of high molecular weight DNA obtained from lymphocytes would be more likely to perform well on the GoldenGate methylation assay than the same amount of DNA from less pure FFPE tissue. Bisulfite conversion of DNA and bsDNA quantitation was performed at The Centre for Applied Genomics, The Hospital for Sick Children, Toronto, Canada.

2.4. Illumina GoldenGate Cancer Panel I Methylation Assay. DNA methylation was evaluated using the Illumina GoldenGate Cancer Panel I Methylation bead array at The Centre for Applied Genomics at the Hospital for Sick Children, Toronto, Canada, and results interpreted with GenomeStudio software [37, 38]. Briefly, bisulfite-treated, biotinylated DNA 
was immobilized on an array matrix of bead-based probe sequences where each bead is coated with universal probes (1,505 different bead types or CpG sites) and represented, on average, 30 times for increased accuracy. Pooled query oligonucleotides wee annealed to the DNA under a controlled hybridization program, and then washed to remove excess or mishybridized oligonucleotides. Hybridized oligonucleotides were then extended and ligated to generate amplifiable templates, followed by PCR using fluorescently labeled universal primers. The methylation status at each $\mathrm{CpG}$ site was determined by calculating $\beta$, which is defined as the ratio of the fluorescent signal from the methylated allele to the sum of the fluorescent signals of both methylated and unmethylated alleles $[33,39]$ and ranged from 0 in the case of completely unmethylated sites to 1 in completely methylated sites.

Background normalization was performed using Illumina's software to minimize the amount of variation in background signals. The background value is derived by averaging the signals of built-in negative control bead types. Outliers were removed using the median absolute deviation method. The built-in negative controls were designed to be thermodynamically equivalent to the regular probes but lacked a specific target in the transcriptome. Negative controls allowed for estimating the expected signal level in the absence of hybridization to a specific target. The negative controls represented unexpressed targets, half of which were expected to be negative. The average signal of the negative controls was subtracted from the probe signals.

2.5. The Cancer Genome Atlas (TCGA). We used publicly available data from 543 serous ovarian carcinomas from TCGA [21] as an independent dataset to compare methylation levels with those from the serous carcinomas evaluated in the current study (only serous ovarian carcinomas were evaluated in TCGA). We also used TCGA data to evaluate Spearman correlation coefficients between tumor methylation levels and gene expression to provide information on functional associations. Methylation in TCGA was evaluated using the Illumina Infinium Human DNA Methylation 27 chip assayed at Johns Hopkins/University of Southern California and expressed as $\beta$-values. Gene expression was evaluated using the Agilent $244 \mathrm{~K}$ Custom Gene Expression G4502A_07 assayed at the University of North Carolina and expressed as fold change between tumor and patient-matched normal tissue (e.g., fallopian tube) on the log2 scale.

2.6. Statistical Analysis. To evaluate reproducibility of the assay, Spearman correlation coefficients were used to compare $\beta$-values from $250 \mathrm{ng}$ versus $400 \mathrm{ng}$ input bsDNA for (i) each patient sample separately and (ii) for patient group data. We also compared reproducibility between replicate samples using $250 \mathrm{ng}$ input bsDNA for the CEPH controls. To evaluate validity, we examined gender-specific $\mathrm{CpG}$ sites among CEPH male and female controls using 250 ng input bsDNA at housekeeping genes from the $\mathrm{X}$ chromosome represented on the GoldenGate methylation assay (e.g., EFNB1, ELK1, FMR1, G6PD, GPC3, and GLA). Methylation of these genes is expected to show gene dosage between males and females owing to gene silencing on one of the two $\mathrm{X}$ chromosomes in female somatic cells that compensates for the single $\mathrm{X}$ chromosome among males [40]. Therefore, we expected to see no or little methylation at these sites among males $(\beta$ values $=0)$ and hemimethylation among females $(\beta$-values $=$ 0.5 ) as previously reported [33]. Spearman correlation coefficients were used to compare $\beta$-values with gene expression in TCGA samples. Statistical tests were two-sided and were implemented with SAS (SAS Institute, NC). Graphs were produced using Stata (Stata Corporation, TX).

Using the $400 \mathrm{ng}$ input bsDNA, we assessed differences in methylation across the three carcinoma types adjusted for multiple comparisons by controlling the False Discovery Rate (FDR) [41]. FDR is based on a moderated $t$-test. Under the null hypothesis of no difference between the two groups, the group labels are interchangeable, and a null distribution of the moderated test statistic can be generated, using 1,000 permutations of the group labels. FDR is calculated based on the null distribution. Methylation differences with FDR below a specified threshold such as $1 \%$ ensured that no more than $1 \%$ of methyl-cytosine calls were false positives. We evaluated the significance of genes differentially methylated across all three ovarian carcinoma types (multiclass procedure), and also for three pair-wise tests comparing serous versus clear cell types, serous versus endometrioid types, and clear cell versus endometrioid types. Prior to analysis, we selected the probe with the maximum $\beta$-value for each of the 808 unique genes using all six carcinomas and tested the methylation status at the gene level. In a secondary approach, we also tested all 1,505 probes.

\section{Results}

3.1. Insufficient Bisulfite DNA Overestimates Methylation Levels. Patients with high-grade serous tumors had FIGO (International Federation of Gynecology and Obstetrics) stage classification IIIC, whereas the two patients with endometrioid tumors had FIGO stages IC and IIB. Two patients with clear cell tumors also had FIGO stages IC and IIB. Spearman correlation coefficients $\left(r^{2}\right)$ of Illumina background-normalized data comparing $400 \mathrm{ng}$ versus $250 \mathrm{ng}$ bsDNA showed a range of $r^{2}$ of $0.41-0.90$ for patient data (Figures 1(a)-1(f)), indicating that the findings with a lower amount of DNA did not always correlate well with the higher amount of DNA. Group data showed improved correlation of $r^{2}=0.90$ (Figure $1(\mathrm{~g})$ ). Indeed, the average methylation across 1,505 CpG loci among the six samples was higher using $250 \mathrm{ng}$ bsDNA (average $\beta$-value $=0.45$, standard deviation $=0.29$ ) than $400 \mathrm{ng}$ bsDNA (average $\beta$-value $=0.36$, standard deviation $=$ 0.32 ), suggesting insufficient bsDNA leads to overestimation of methylation. Furthermore, because the reproducibility between duplicate HapMap samples using $250 \mathrm{ng}$ bsDNA was $r^{2}=0.76$ for the CEPH male (Figure $1(\mathrm{~h})$ ) and $r^{2}=0.92$ for the CEPH female (Figure 1(i)), we infer that the lower amount of $250 \mathrm{ng}$ can bias methylation results even with non-FFPE sources of DNA. In support of this deduction, we observed that methylation of $\mathrm{X}$ chromosome loci was close to zero for one replicate sample of the CEPH male, as expected, but higher for the other CEPH male replicate (Table 1 ). $\beta$-values 


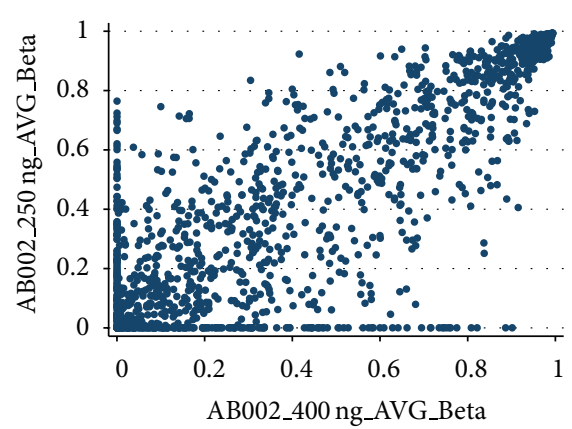

(a) $r^{2}=0.80$

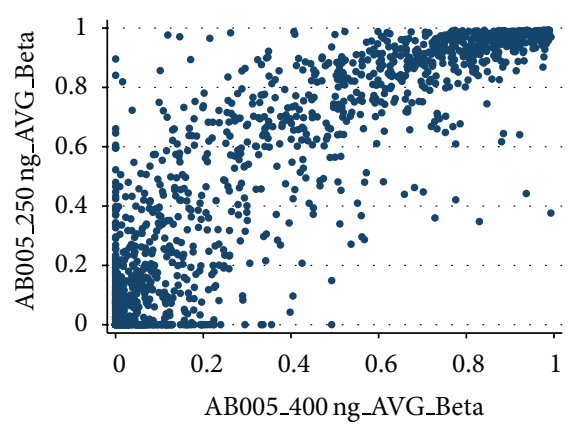

(d) $r^{2}=0.88$

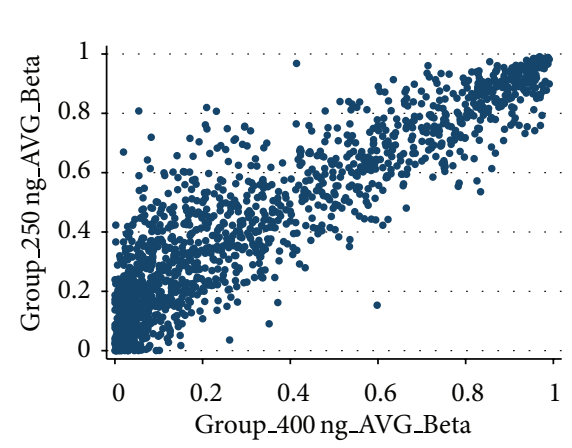

(g) $r^{2}=0.90$

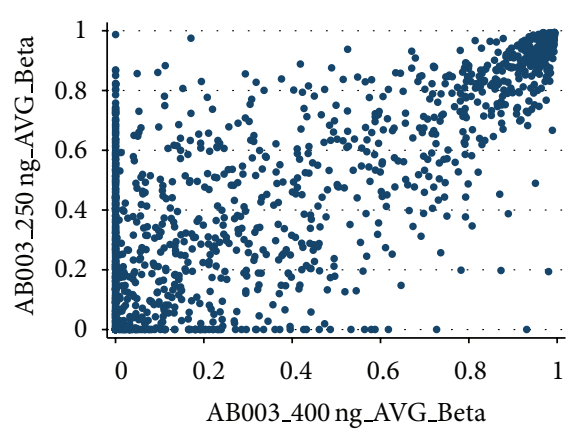

(b) $r^{2}=0.76$

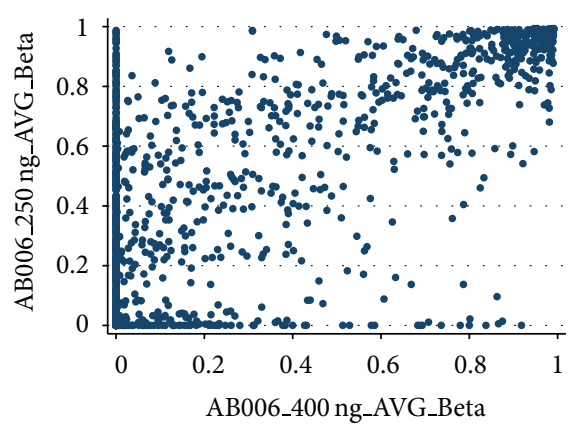

(e) $r^{2}=0.69$

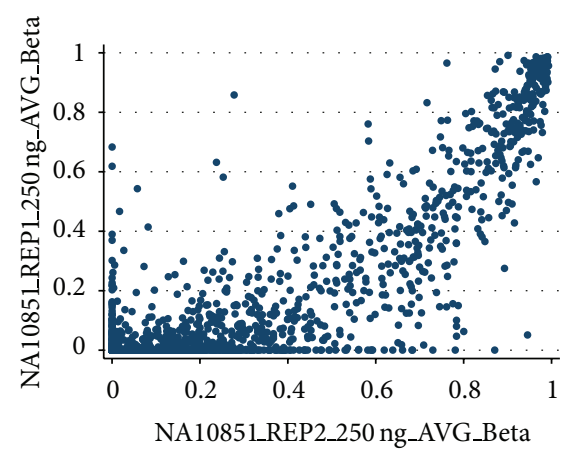

(h) $r^{2}=0.76$

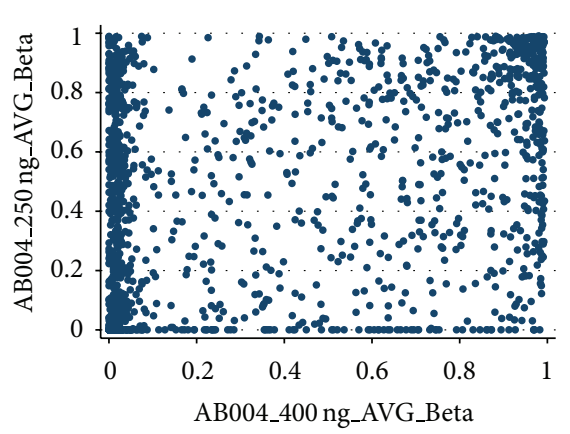

(c) $r^{2}=0.41$

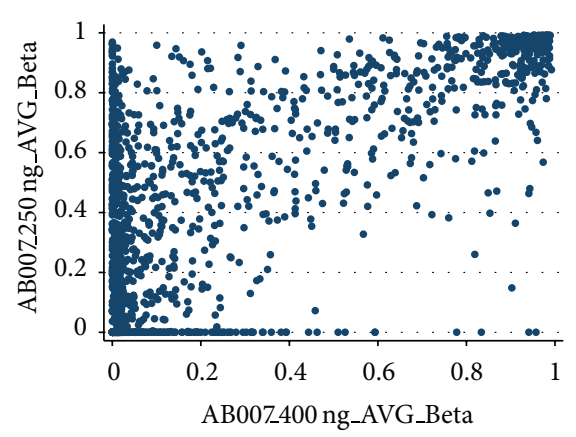

(f) $r^{2}=0.64$

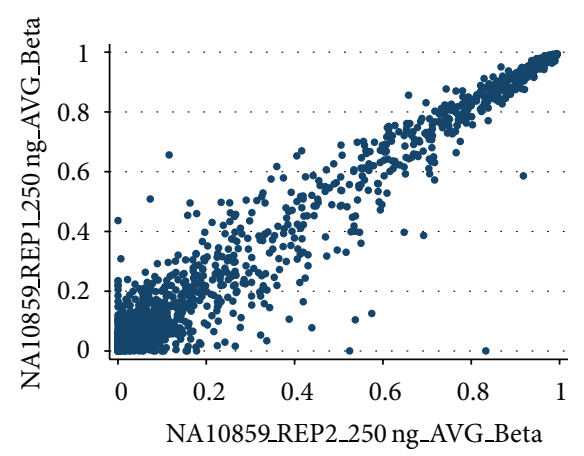

(i) $r^{2}=0.92$

FIGURE 1: Scatter plots of $\beta$-values and Spearman correlation coefficients $\left(r^{2}\right)$. (a) to (f), patient data comparing $250 \mathrm{ng}$ versus $400 \mathrm{ng}$ bsDNA for high-grade serous ((a) and (b)), endometrioid ((c) and (d)), and clear cell ((e) and (f)) carcinomas; (g), averaged group data comparing $250 \mathrm{ng}$ versus $400 \mathrm{ng}$ bsDNA; (h) to (i), reproducibility plots of $250 \mathrm{ng}$ bsDNA for a CEPH male (h) and a CEPH female (i).

were closer to one than to hemimethylation for several CpG loci for the female replicate samples.

\subsection{Endometrioid Ovarian Carcinomas Exhibit Fewer Methy-} lated Loci. Figure 2 shows the extent of methylation at $\mathrm{CpG}$ loci on autosomal chromosomes in the three different ovarian carcinoma types by patient using the higher $400 \mathrm{ng}$ bsDNA amount. Although the number of samples is small, very low levels $(\beta$-value $<0.1)$ of methylated loci were seen in approximately $50 \%$ of the endometrioid carcinoma types compared to $30 \%$ to $40 \%$ of the serous and clear cell types.

\subsection{Differentially Methylated Loci Distinguish Ovarian Carci-} noma Histological Types. The multiclass procedure identified two genes that were differentially methylated across all three carcinoma types at the $1 \%$ FDR level: THBS2 (FDR < $0.1 \%)$ and $E R G(\mathrm{FDR}<0.1 \%)$. Both genes showed higher methylation at $\mathrm{CpG}$ sites among clear cell carcinomas (Table 2). The remaining genes had FDR values larger than 38\%. Next, we conducted pair-wise tests between ovarian carcinoma types. Comparing clear cell and endometrioid types, THBS2, ERG, MST1R, ISL1, LY6G6E, and NRG1 were differentially methylated at $1 \%$ FDR (Table 2). Comparing serous and clear cell types, only ERG was differentially methylated at $1 \%$ FDR. No gene was differentially methylated at 1\% FDR between serous and endometrioid types.

3.4. Gene Expression Does Not Always Correlate with CGI Promoter Methylation. We compared the median $\beta$-values of the aforementioned genes for the two serous ovarian carcinomas in the current investigation (Table 2) with those obtained from 543 serous ovarian carcinomas in the TCGA sample 
TABLE 1: Average $\beta$-values for CEPH control replicates at 6 housekeeping X-chromosome genes.

\begin{tabular}{|c|c|c|c|c|c|}
\hline Target CpG (Gene_Probe) ${ }^{\mathrm{a}}$ & CpG locus ID & $\begin{array}{c}\text { NA10851 replicate } 1 \\
\text { Male }\end{array}$ & $\begin{array}{c}\text { NA10851 replicate } 2 \\
\text { Male }\end{array}$ & $\begin{array}{c}\text { NA10859 replicate } 1 \\
\text { Female } \\
\end{array}$ & $\begin{array}{c}\text { NA10859 replicate } 2 \\
\text { Female }\end{array}$ \\
\hline EFNB1_E69_F & cg09459058 & 0.0126 & 0.2023 & 0.7337 & 0.6362 \\
\hline EFNB1_P136_R & $\operatorname{cg} 14717445$ & 0 & 0.0464 & 0.7696 & 0.7287 \\
\hline EFNB1_P17_F & $\operatorname{cg} 22151131$ & 0.0347 & 0.4068 & 0.9331 & 0.9314 \\
\hline ELK1_E156_F & $\operatorname{cg} 00983071$ & 0 & 0.3000 & 0.6910 & 0.6078 \\
\hline ELK1_E53_F & $\operatorname{cg} 12482901$ & 0 & 0.2093 & 0.8778 & 0.8242 \\
\hline ELK1_P195_R & cg13072663 & 0.0609 & 0.1694 & 0.8192 & 0.7816 \\
\hline ELK1_P569_R & cg11111083 & 0.0635 & 0.2362 & 0.8847 & 0.8524 \\
\hline FMR1_P62_R & $\operatorname{cg} 26857803$ & 0 & 0 & 0.8810 & 0.8428 \\
\hline G6PD_E190_F & $\operatorname{cg} 10661350$ & 0 & 0.0003 & 0.6423 & 0.6107 \\
\hline G6PD_P1065_R & $\operatorname{cg} 26368202$ & 0 & 0 & 0.9371 & 0.9436 \\
\hline G6PD_P196_F & cg27592930 & 0.0674 & 0.1537 & 0.6010 & 0.6159 \\
\hline G6PD_P597_F & cg26178557 & 0 & 0.7808 & 0.9157 & 0.9148 \\
\hline GLA_E98_R & cg15481221 & 0.0667 & 0.0802 & 0.7609 & 0.6608 \\
\hline GLA_P112_F & cg20747453 & 0 & 0 & 0.9764 & 0.9668 \\
\hline GLA_P343_R & cg24484149 & 0 & 0.0134 & 0.3123 & 0.2510 \\
\hline GPC3_E72_F & cg27496708 & 0 & 0 & 0.6807 & 0.7110 \\
\hline GPC3_P235_R & cg07504028 & 0.0240 & 0.0475 & 0.8579 & 0.8565 \\
\hline
\end{tabular}

${ }^{a}$ Probe annotation according to the Illumina GoldenGate Cancer Panel I methylation assay; all loci are located within CpG islands.

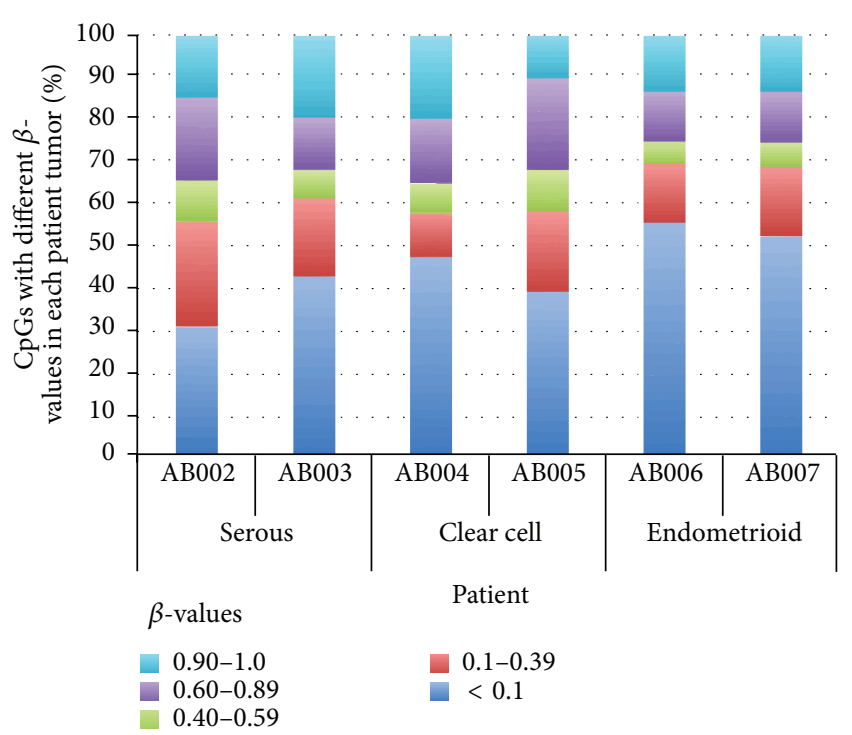

FIGURE 2: Stack column graph showing the extent of methylation in the three ovarian carcinoma types using 1,421 autosome CpG loci. The extent of methylation in each ovarian carcinoma is represented by the different percentages of $\beta$-value categories as shown in the legend.

(Table 3). Generally, both groups showed low or negligible $\beta$-values for ERG probes, with values varying, on average, by a two-fold factor for the other genes. In making this comparison, however, we note that different $\mathrm{CpG}$ coordinates for each gene were represented on the two assays. In analyses that compared methylation and gene expression values using samples from the TCGA, only the probes targeting CpG loci in MST1R showed strong inverse Spearman correlation coefficients $(r=-0.70$ for position $49,915,857 \mathrm{bp}$ and $r=-0.65$ for position 49,916,155 bp, both $P<0.0001$ ) (Figure 3(c)). There were weak correlations between methylation and gene expression for the remaining genes/probes.

In the secondary approach, which evaluated all 1,505 CpG loci at $<0.1 \%$ FDR, THBS2_P605_R, ERG_E28_F, EYA4_ E277_F, and NPY_P295_F probes were differentially methylated across all three carcinoma types, THBS2_P605_R and PTGS2_P524_R were differentially methylated between endometrioid and clear cell types, IL11_E232_F was differentially methylated between serous and endometrioid types, and IGF2AS_P203_F and ERG_E28_F were differentially methylated between serous and clear cell types (data not shown). No other probes were differentially methylated at $<5 \%$ FDR.

\section{Discussion}

This study used gene-level and locus-level approaches to investigate associations between methylation and ovarian carcinoma types. Both approaches identified THBS2 (thrombospondin 2) and ERG (erythroblastosis virus E26 oncogene homolog) genes to be significantly differentially methylated across all three ovarian carcinoma histological types and, specifically, between endometrioid and clear cell carcinomas and suggested that different biological pathways are important in the natural history of the histological types. The endometrioid and clear cell types comprise approximately $10 \%$ each of the epithelial ovarian carcinomas [15]. Morphologically, the cell types are quite different [42] and show differential expression of certain biomarkers including hormone receptors and HNF1B [43]. Importantly, expression of 


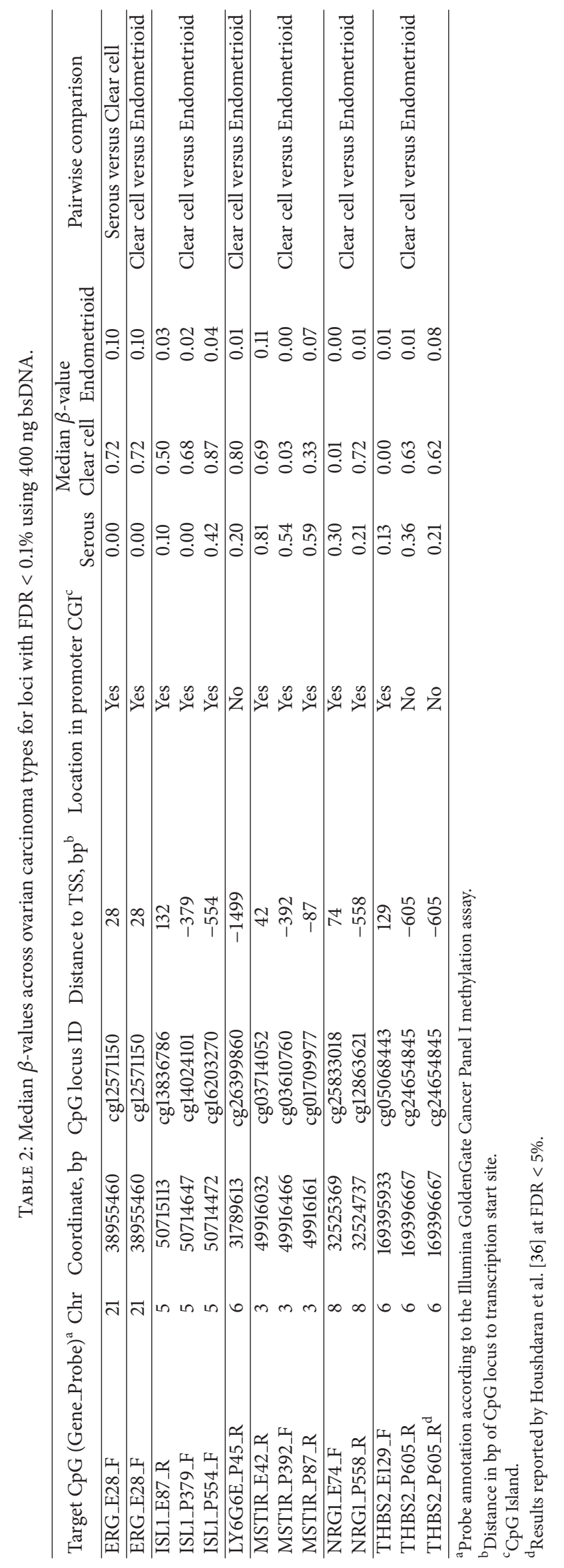




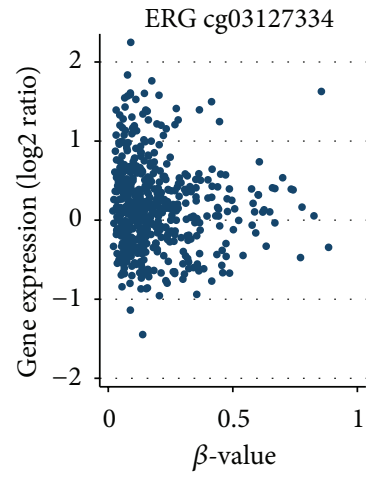

(a) $r^{2}=-0.07$

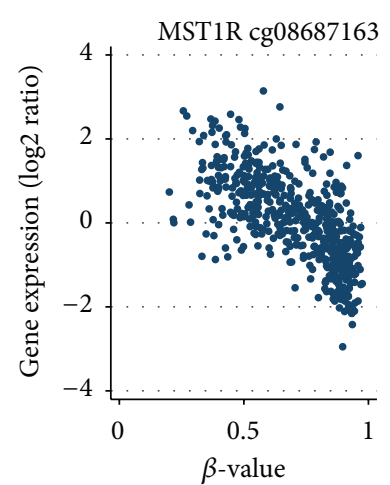

(e) $r^{2}=-0.70$

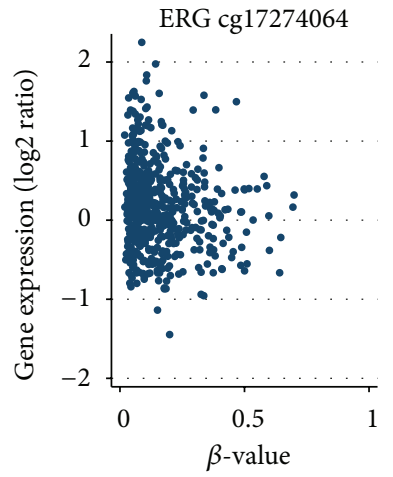

(b) $r^{2}=-0.11$

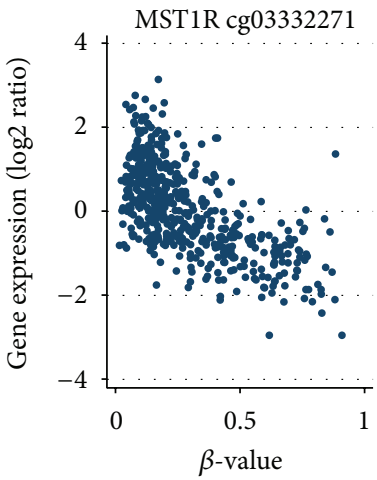

(f) $r^{2}=-0.65$

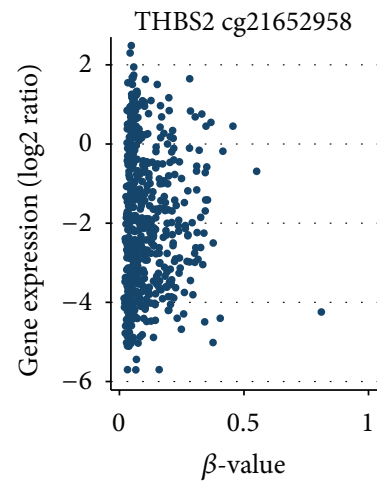

(i) $r^{2}=0.10$

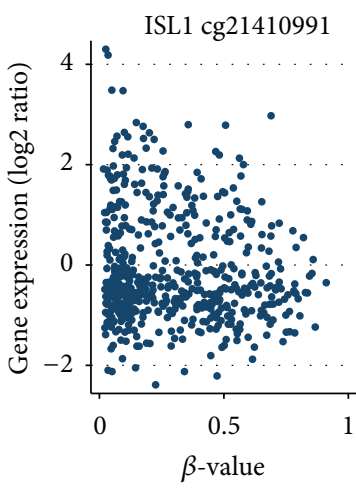

(c) $r^{2}=-0.08$

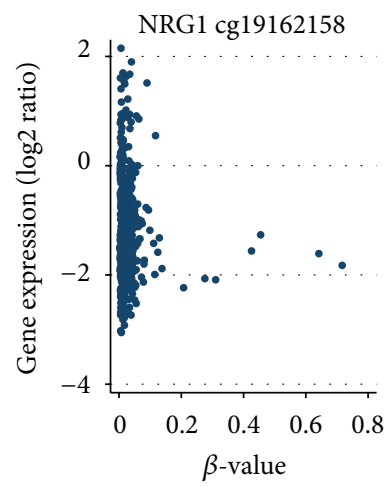

(g) $r^{2}=-0.01$

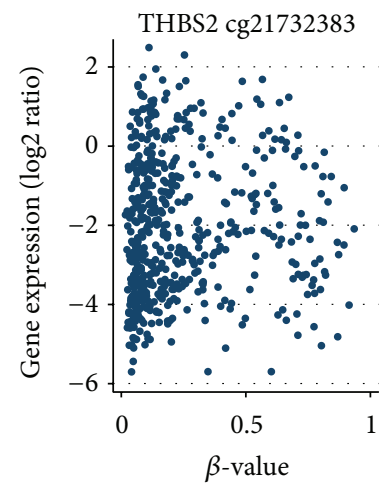

(j) $r^{2}=0.15$

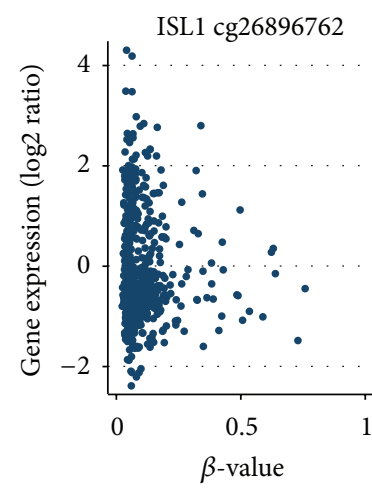

(d) $r^{2}=0.02$

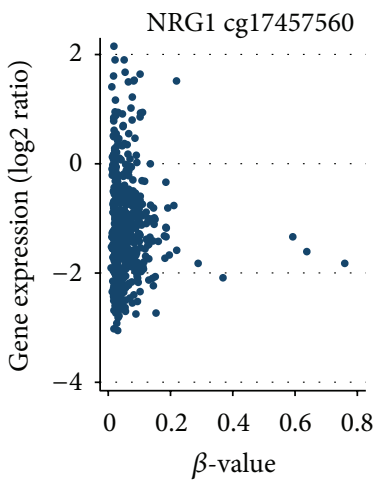

(h) $r^{2}=0.03$

Figure 3: Scatter plots of $\beta$-values versus gene expression ( $\log 2$ ratio) and Spearman correlation coefficients $\left(r^{2}\right)$ from 543 serous ovarian carcinomas from The Cancer Genome Atlas. Two CpG loci were evaluated per gene. (a) and (b), ERG; (c) and (d), ISL1; (e) and (f), MST1R; (g) and (h), NRG1; (i) and (j), THSB2. $\beta$-values were not available for LY6G6E.

HNF1B in ovarian clear cell, compared to high-grade serous, histological types was associated with differentially methylated promoter regions [44]. Endometriosis may be the cell of origin of the endometrioid and clear cell cancers $[45,46]$, yet little is known of the mechanism by which these two cancer types are derived from the same precursor lesion. There is compelling evidence to support the role of epigenetic alterations in their pathogenesis [47-52], and differential methylation of THBS 2 and ERG could provide a new insight into biological pathways.
The finding with THBS2 is particularly noteworthy when interpreted within the context of the study by Houshdaran et al. [36]. That study evaluated methylation between fifteen serous, nine endometrioid, and three clear cell ovarian carcinomas using the same Illumina GoldenGate methylation platform. $\beta$-values at the THBS2_P605_R probe across histological types in our investigation were remarkably similar to those reported by Houshdaran et al. [36]. Identification of the same differentially methylated loci in the current study, therefore, can be considered a replication of earlier findings despite 
TABLE 3: Median $\beta$-values at selected genes ${ }^{\mathrm{a}}$ in 543 serous ovarian carcinomas from The Cancer Genome Atlas.

\begin{tabular}{|c|c|c|c|c|c|c|c|}
\hline Target gene $^{\mathrm{b}}$ & Chr & Coordinate, bp & CpG locus ID & Distance to TSS, $\mathrm{bp}^{\mathrm{c}}$ & Location in promoter $\mathrm{CGI}^{\mathrm{d}}$ & $\beta$-value & (Min., max.) \\
\hline ERG & 21 & 38955504 & cg03127334 & 16 & Yes & 0.13 & $0.02,0.88$ \\
\hline ERG & 21 & 38955762 & $\operatorname{cgl} 17274064$ & 27 & No & 0.11 & $0.02,0.70$ \\
\hline ISL1 & 5 & 50714208 & cg21410991 & 81 & Yes & 0.24 & $0.02,0.91$ \\
\hline ISL1 & 5 & 50715118 & $\operatorname{cg} 26896762$ & 9 & Yes & 0.07 & $0.02,0.76$ \\
\hline LY6G6E & 6 & - & - & - & - & - & - \\
\hline MST1R & 3 & 49915857 & $\operatorname{cg} 08687163$ & 21 & Yes & 0.74 & $0.20,0.97$ \\
\hline MST1R & 3 & 49916155 & $\operatorname{cg} 03332271$ & 8 & Yes & 0.20 & $0.02,0.91$ \\
\hline NRG1 & 8 & 32524969 & $\operatorname{cg} 19162158$ & 32 & Yes & 0.01 & $0.003,0.72$ \\
\hline NRG1 & 8 & 32525393 & $\operatorname{cg} 17457560$ & 9 & Yes & 0.04 & $0.01,0.76$ \\
\hline THBS2 & 6 & 169395886 & cg21652958 & 17 & Yes & 0.07 & $0.02,0.81$ \\
\hline THBS2 & 6 & 169396617 & cg21732383 & 55 & No & 0.14 & $0.02,0.93$ \\
\hline
\end{tabular}

${ }^{a}$ Genes found to be differentially methylated in the current study.

${ }^{\mathrm{b}}$ Annotation according to the Illumina Infinium Human DNA Methylation 27 assay.

${ }^{c}$ Distance in bp of CpG locus to transcription start site.

${ }^{\mathrm{d}} \mathrm{CpG}$ Island.

${ }^{\mathrm{e}} \beta$-values not available in Illumina Infinium Human Methylation $27 \mathrm{~K}$ chip.

the small number of clear cell tumors evaluated in both studies. THBS2 is located on $6 \mathrm{p} 27$ and encodes a member of the thrombospondin family. Thrombospondin 2 mediates cell-to-cell and cell-to-matrix interactions and may function as either a potent inhibitor $[53,54]$ or stimulator $[55,56]$ of tumor growth and angiogenesis in ovarian carcinoma, although no studies evaluated thrombospondin 2 according to ovarian histological type. Interestingly, the gene product of related THBS1 is expressed in ovarian cancer cell lines and ascites fluid of patients [57].

Unlike the current investigation, ERG was not differentially methylated in the study by Houshdaran et al. [36]. ERG, located on 21q22.3, encodes a member of the erythroblast transformation-specific (ETS) family of transcription factors; members of this family are key regulators of embryonic development, cellular proliferation, differentiation, angiogenesis, inflammation, and apoptosis. $E R G$ is perhaps best known for the gene fusion product, TMPSSR2-ERG, which is common in approximately $50 \%$ of prostate cancers [58].

Although macrophage stimulating 1 receptor (MST1R) was not differentially methylated across histological types in the study by Houshdaran et al. [36], that study did report that three of eight CpG loci in MST1R were strongly inversely correlated $\left(r^{2}:-0.88\right.$ to -0.96$)$ with gene expression in ovarian cancer cell lines. We found similar inverse correlations $\left(r^{2}:-0.65\right.$ to -0.70$)$ with gene expression in the TCGA data. $M S T 1 R$ is located on 3p21.3 and encodes a cell surface receptor for macrophage-stimulating protein with tyrosine kinase activity.

Other genes evaluated in the current study did not show an inverse relation between CGI methylation and gene expression. This is not surprising. Although DNA methylation in $5^{\prime}$ promoter regions causes transcriptional repression [1], mammalian tissue and cell type-specific methylation are present in a small percentage of $5^{\prime}$ CGI promoters, and most CGIs are normally unmethylated in somatic cells [6]. This plasticity permits regulation of gene expression by transcription factors, except when CGI promoter methylation is associated with maintenance of long-term silencing, for example, $\mathrm{X}$-chromosome inactivation. In contrast, data from cancer cells suggest that gene silencing and transcriptional activity by mechanisms other than CGI promoter methylation may correlate inversely with gene expression independent of CGI promoter methylation [10, 59-63]. Thus, more thorough investigation of associations between cytosine methylation and gene expression will require evaluation of nonpromoter CGI regions and novel transcripts and alternate slice forms, which can be achieved with next generation sequencing methods [64].

We found that the minimal amount of $250 \mathrm{ng}$ bsDNA recommended by the manufacturer [31-33] resulted in higher overall $\beta$-values compared to $400 \mathrm{ng}$ bsDNA. The effect appeared to overestimate the methylation of DNA cytosines, although the variability (standard deviation) was similar between the amounts. Overestimation of methylation levels will not bias relative risk associations in epidemiologic studies if methylation levels are overestimated to the same extent across all probes and for each sample under study. However, this was not true in the current investigation because evaluation of duplicate samples of the HapMap controls at $\mathrm{X}$-chromosome housekeeping genes showed concordance of $\beta$-values for some probes but not for others. It is unlikely that this differential outcome is the result of laboratory error during sample preparation. Although discontinued as a platform in March 2010, the assay remains available to researchers for custom design. We note that other Illumina methylation platforms, such as the Infinium $27 \mathrm{~K}$ chip (also discontinued) and the $450 \mathrm{~K}$ chip require a minimum of $500 \mathrm{ng}$ bsDNA. The Infinium protocols incorporate a whole-genome amplification (WGA) step following bisulfite-conversion rather than a PCR step used in the GoldenGate protocol. WGA DNA is sensitive to the quality and purity of the DNA. Because of 
this, the Infinium protocols have been recently modified to include a restoration step that elongates FFPE-derived DNA to optimize the $450 \mathrm{~K}$ array analysis with this type of DNA. We believe the findings from our evaluation of the existing GoldenGate protocol will be useful to inform the protocols of others who proceed with any methylation assays using FFPEderived DNA.

Limitations of this study include the small sample size for each histology and the lack of an independent method to validate methylation status of loci; thus, the findings for methylated loci should be interpreted cautiously. Further, the Illumina GoldenGate Cancer Panel I methylation array lacked the increased coverage of the Illumina $450 \mathrm{~K}$ bead chip; however, a limitation of all hybridization-based techniques is the inaccessibility to measure methylation at repetitive sequences, which encompass nearly half of the 28 million $\mathrm{CpG}$ sites in the methylome and are a critical component of epigenetic gene regulation $[65,66]$. The strength of this investigation is the replication of a previously reported differentially methylated locus between endometrioid and clear cell types. Although this does not prove validity, reproducible findings provide credibility that an initial finding may not be due to chance [67]. Our study, therefore, contributes to the identification of novel methylated loci that may provide new insight into biological pathways that distinguish their development.

\section{Conclusions}

The reproducibility of the Illumina GoldenGate Cancer Panel I methylation assay may be improved using input bsDNA closer to the amounts recommended for the $450 \mathrm{~K}$ bead chip ( $\geq 400 \mathrm{ng}$ bsDNA). Given the complexity and heterogeneity of ovarian carcinomas, evaluating wide-spread epigenomic events could aid to further clarify histological type heterogeneity, which would improve our understanding of the natural history of the disease and identify potential targets for improved treatment strategies.

\section{Conflict of Interests}

The authors declare that there is no conflict of interests regarding the publication of this paper.

\section{Authors' Contribution}

Linda E. Kelemen conceived the study design, acquired the data and funding, and drafted the paper; Martin Köbel performed the pathologic review and contributed to data interpretation; Angela Chan performed all laboratory methods related to DNA preparation; Soreh Taghaddos and Irina Dinu implemented and interpreted statistical analysis; all authors read and approved the final paper.

\section{Acknowledgments}

Funding was provided by the James D Macdonald and Lola Eleanor Macdonald Memorial Endowment through the University of Calgary and by the Alberta Cancer Research Institute (Project no. 24258). LEK is supported by the Canadian
Institutes of Health Research New Investigator Award (MSH87734). The authors thank Dr. Tara Paton from The Centre for Applied Genomics, The Hospital for Sick Children, Toronto, Canada, for performing the Illumina GoldenGate Cancer Panel I Methylation assay and quality control data interpretation. The results published here are in part based upon data generated by The Cancer Genome Atlas Project established by the National Cancer Institute and National Human Genome Research Institute. Information about TCGA and the investigators and institutions that constitute the TCGA research network can be found at http://cancergenome.nih.gov/.

\section{References}

[1] P. A. Jones and S. B. Baylin, "The epigenomics of cancer," Cell, vol. 128, no. 4, pp. 683-692, 2007.

[2] A. P. Feinberg, "Epigenetics at the epicenter of modern medicine," Journal of the American Medical Association, vol. 299, no. 11, pp. 1345-1350, 2008.

[3] T. Mohandas, R. S. Sparkes, and L. J. Shapiro, "Reactivation of an inactive human $\mathrm{X}$ chromosome: evidence for X inactivation by DNA methylation," Science, vol. 211, no. 4480, pp. 393-396, 1981.

[4] F. Antequerra, J. Boyes, and A. Bird, "High levels of de novo methylation and altered chromatin structure at CpG islands in cell lines," Cell, vol. 62, no. 3, pp. 503-514, 1990.

[5] D. J. Pulford, J. G. Falls, J. K. Killian, and R. L. Jirtle, "Polymorphisms, genomic imprinting and cancer susceptibility," Mutation Research, vol. 436, no. 1, pp. 59-67, 1999.

[6] A. Bird, "DNA methylation patterns and epigenetic memory," Genes and Development, vol. 16, no. 1, pp. 6-21, 2002.

[7] R. Lister, M. Pelizzola, R. H. Dowen et al., "Human DNA methylomes at base resolution show widespread epigenomic differences," Nature, vol. 462, no. 7271, pp. 315-322, 2009.

[8] R. S. Illingworth and A. P. Bird, "CpG islands-'a rough guide", FEBS Letters, vol. 583, no. 11, pp. 1713-1720, 2009.

[9] S. K. Murphy, "Targeting the epigenome in ovarian cancer," Future Oncology, vol. 8, no. 2, pp. 151-164, 2012.

[10] R. A. Irizarry, C. Ladd-Acosta, B. Wen et al., "The human colon cancer methylome shows similar hypo- and hypermethylation at conserved tissue-specific CpG island shores," Nature Genetics, vol. 41, no. 2, pp. 178-186, 2009.

[11] A. P. Feinberg, R. Ohlsson, and S. Henikoff, "The epigenetic progenitor origin of human cancer," Nature Reviews Genetics, vol. 7, no. 1, pp. 21-33, 2006.

[12] K. D. Hansen, W. Timp, H. C. Bravo et al., "Increased methylation variation in epigenetic domains across cancer types," Nature Genetics, vol. 43, no. 8, pp. 768-775, 2011.

[13] J. Ferlay, H.-R. Shin, F. Bray, D. Forman, C. Mathers, and D. M. Parkin, "Estimates of worldwide burden of cancer in 2008: GLOBOCAN 2008," International Journal of Cancer, vol. 127, no. 12, pp. 2893-2917, 2010.

[14] N. Auersperg, A. S. T. Wong, K.-C. Choi, S. K. Kang, and P. C. K. Leung, "Ovarian surface epithelium: biology, endocrinology, and pathology," Endocrine Reviews, vol. 22, no. 2, pp. 255-288, 2001.

[15] M. Köbel, S. E. Kalloger, D. G. Huntsman et al., "Differences in tumor type in low-stage versus high-stage ovarian carcinomas," International Journal of Gynecological Pathology, vol. 29, no. 3, pp. 203-211, 2010. 
[16] K.-K. Wong and D. Gershenson, "The continuum of serous tumors of low malignant potential and low-grade serous carcinomas of the ovary," Disease Markers, vol. 23, no. 5-6, pp. 377387, 2007.

[17] I.-M. Shih and R. J. Kurman, "Ovarian tumorigenesis: a proposed model based on morphological and molecular genetic analysis," American Journal of Pathology, vol. 164, no. 5, pp. 15111518, 2004.

[18] G. Singer, R. Stöhr, L. Cope et al., "Patterns of p53 mutations separate ovarian serous borderline tumors and low- and highgrade carcinomas and provide support for a new model of ovarian carcinogenesis: a mutational analysis with immunohistochemical correlation," American Journal of Surgical Pathology, vol. 29, no. 2, pp. 218-224, 2005.

[19] M. H. Roh, D. Kindelberger, and C. P. Crum, "Serous tubal intraepithelial carcinoma and the dominant ovarian mass: clues to serous tumor origin?" American Journal of Surgical Pathology, vol. 33, no. 3, pp. 376-383, 2009.

[20] C. A. Barton, N. F. Hacker, S. J. Clark, and P. M. O’Brien, “DNA methylation changes in ovarian cancer: implications for early diagnosis, prognosis and treatment," Gynecologic Oncology, vol. 109, no. 1, pp. 129-139, 2008.

[21] D. Bell, A. Berchuck, M. Birrer et al., "Integrated genomic analyses of ovarian carcinoma," Nature, vol. 474, no. 7353, pp. 609615, 2011.

[22] J. Z. Press, A. De Luca, N. Boyd et al., "Ovarian carcinomas with genetic and epigenetic BRCA1 loss have distinct molecular abnormalities," BMC Cancer, vol. 8, article 17, 2008.

[23] A. Rathi, A. K. Virmani, J. O. Schorge et al., "Methylation profiles of sporadic ovarian tumors and nonmalignant ovaries from high-risk women," Clinical Cancer Research, vol. 8, no. 11, pp. 3324-3331, 2002.

[24] G. Strathdee, K. Appleton, M. Illand et al., "Primary ovarian carcinomas display multiple methylator phenotypes involving known tumor suppressor genes," American Journal of Pathology, vol. 158, no. 3, pp. 1121-1127, 2001.

[25] M. Esteller, P. G. Corn, S. B. Baylin, and J. G. Herman, "A gene hypermethylation profile of human cancer," Cancer Research, vol. 61, no. 8, pp. 3225-3229, 2001.

[26] C. Wang, A. Horiuchi, T. Imai et al., "Expression of BRCA1 protein in benign, borderline, and malignant epithelial ovarian neoplasms and its relationship to methylation and allelic loss of the BRCA1 gene," Journal of Pathology, vol. 202, no. 2, pp. 215223, 2004.

[27] N. Collins, R. Wooster, and M. R. Stratton, "Absence of methylation of $\mathrm{CpG}$ dinucleotides within the promoter of the breast cancer susceptibility gene BRCA2 in normal tissues and in breast and ovarian cancers," British Journal of Cancer, vol. 76, no. 9, pp. 1150-1156, 1997.

[28] E. Gras, J. Cortes, O. Diez et al., "Loss of heterozygosity on chromosome 13q12-q14, BRCA-2 mutations and lack of BRCA2 promoter hypermethylation in sporadic epithelial ovarian tumors," Cancer, vol. 92, no. 4, pp. 787-795, 2001.

[29] J. L. Hilton, J. P. Geisler, J. A. Rathe, M. A. Hattermann-Zogg, B. Deyoung, and R. E. Buller, "Inactivation of BRCA1 and BRCA2 in ovarian cancer," Journal of the National Cancer Institute, vol. 94, no. 18, pp. 1396-1406, 2002.

[30] J. F. Costello, M. C. Frühwald, D. J. Smiraglia et al., "Aberrant CpG-island methylation has non-random and tumour-typespecific patterns," Nature Genetics, vol. 24, no. 2, pp. 132-138, 2000 .
[31] J. K. Killian, S. Bilke, S. Davis et al., "In Genome-wide methylation profile of follicular lymphoma reveals distinct on- and off-island epigenotype [abstract no 32]," in Proceedings of the 99th Annual Meeting of the American Association for Cancer Research, AACR, San Diego, Calif, USA, April 2008.

[32] Illumina, Inc., Methylation profiling of FFPE samples. Technical Note: Illumina Epigenetics, 2008, http://www.illumina.com.

[33] M. Bibikova, Z. Lin, L. Zhou et al., "High-throughput DNA methylation profiling using universal bead arrays," Genome Research, vol. 16, no. 3, pp. 383-393, 2006.

[34] C. Ladd-Acosta, J. Pevsner, S. Sabunciyan et al., "DNA methylation signatures within the human brain," American Journal of Human Genetics, vol. 81, no. 6, pp. 1304-1315, 2007.

[35] The International HapMap Consortium, "The international HapMap project," Nature, vol. 426, no. 6968, pp. 789-796, 2003.

[36] S. Houshdaran, S. Hawley, C. Palmer et al., "DNA methylation profiles of ovarian epithelial carcinoma tumors and cell lines," PLoS ONE, vol. 5, no. 2, Article ID e9359, 2010.

[37] F. J. Steemers and K. L. Gunderson, "Illumina, Inc," Pharmacogenomics, vol. 6, no. 7, pp. 777-782, 2005.

[38] A. Oliphant, D. L. Barker, J. R. Stuelpnagel, and M. S. Chee, "BeadArray technology: enabling an accurate, cost-effective approach to high-throughput genotyping," BioTechniques, vol. 32, no. 6, pp. S56-S61, 2002.

[39] H. T. Bjornsson, M. I. Sigurdsson, M. D. Fallin et al., "Intraindividual change over time in DNA methylation with familial clustering," Journal of the American Medical Association, vol. 299, no. 24, pp. 2877-2883, 2008.

[40] L. Carrel and H. F. Willard, "X-inactivation profile reveals extensive variability in X-linked gene expression in females," Nature, vol. 434, no. 7031, pp. 400-404, 2005.

[41] V. G. Tusher, R. Tibshirani, and G. Chu, "Significance analysis of microarrays applied to the ionizing radiation response," Proceedings of the National Academy of Sciences of the United States of America, vol. 98, no. 9, pp. 5116-5121, 2001.

[42] F. A. Tavassoulu and P. Devilee, World Health Organization Classification of Tumors. Pathology and Genetics of Tumors of the Breast and Female Genital Organs, IARC Press, Lyon, France, 2003.

[43] S. E. Kalloger, M. Köbel, S. Leung et al., "Calculator for ovarian carcinoma subtype prediction," Modern Pathology, vol. 24, no. 4, pp. 512-521, 2011.

[44] H. Shen, B. L. Fridley, H. Song et al., "Epigenetic analysis leads to identification of HNF1B as a subtype-specific susceptibility gene for ovarian cancer," Nature Communications, vol. 4, article 1628, 2013.

[45] C. L. Pearce, C. Templeman, M. A. Rossing et al., "Association between endometriosis and risk of histological subtypes of ovarian cancer: a pooled analysis of case-control studies," The Lancet Oncology, vol. 13, no. 4, pp. 385-394, 2012.

[46] R. J. Kurman and T. G. McConnell, "Characterization and comparison of precursors of ovarian and endometrial carcinoma: parts I and II," International Journal of Surgical Pathology, vol. 18, no. 3, supplement, pp. 181S-189S, 2010.

[47] J. Liu, C. T. Albarracin, K.-H. Chang et al., "Microsatellite instability and expression of hMLH1 and hMSH2 proteins in ovarian endometrioid cancer," Modern Pathology, vol. 17, no. 1, pp. 7580, 2004.

[48] K. Q. Cai, C. Albarracin, D. Rosen et al., "Microsatellite instability and alteration of the expression of hMLH1 and hMSH2 in ovarian clear cell carcinoma," Human Pathology, vol. 35, no. 5, pp. 552-559, 2004. 
[49] K. C. Wiegand, S. P. Shah, O. M. Al-Agha et al., "ARID1A mutations in endometriosis-associated ovarian carcinomas," The New England Journal of Medicine, vol. 363, no. 16, pp. 1532-1543, 2010.

[50] S. Jones, T.-L. Wang, I.-M. Shih et al., "Frequent mutations of chromatin remodeling gene ARID1A in ovarian clear cell carcinoma," Science, vol. 330, no. 6001, pp. 228-231, 2010.

[51] M. Widschwendter, S. Apostolidou, A. A. Jones et al., "HOXA methylation in normal endometrium from premenopausal women is associated with the presence of ovarian cancer: a proof of principle study," International Journal of Cancer, vol. 125, no. 9, pp. 2214-2218, 2009.

[52] Q. Wu, R. A. Lothe, T. Ahlquist et al., "DNA methylation profiling of ovarian carcinomas and their in vitro models identifies HOXA9, HOXB5, SCGB3A1, and CRABP1 as novel targets," Molecular Cancer, vol. 6, article 45, 2007.

[53] T. Hawighorst, P. Velasco, M. Streit et al., “Thrombospondin-2 plays a protective role in multistep carcinogenesis: a novel host anti-tumor defense mechanism," EMBO Journal, vol. 20, no. 11, pp. 2631-2640, 2001.

[54] A. Czekierdowski, S. Czekierdowska, J. Danilos et al., "Microvessel density and CPG island methylation of THBS2 gene in malignant ovarian tumors," Journal of Physiology and Pharmacology, vol. 59, supplement 4, pp. 53-65, 2008.

[55] J. Kodama, I. Hashimoto, N. Seki et al., "Thrombospondin-1 and -2 messenger RNA expression in epithelial ovarian tumor," Anticancer Research B, vol. 21, no. 4, pp. 2983-2987, 2001.

[56] N. Lopes, D. Gregg, S. Vasudevan, H. Hassanain, P. Goldschmidt-Clermont, and H. Kovacic, "Thrombospondin 2 regulates cell proliferation induced by Racl redox-dependent signaling," Molecular and Cellular Biology, vol. 23, no. 15, pp. 5401-5408, 2003.

[57] V. Kulasingam, M. P. Pavlou, and E. P. Diamandis, "Integrating high-throughput technologies in the quest for effective biomarkers for ovarian cancer," Nature Reviews Cancer, vol. 10, no. 5, pp. 371-378, 2010.

[58] R.-S. Mani, M. K. Iyer, Q. Cao et al., "TMPRSS2-ERG-mediated feed-forward regulation of wild-type ERG in human prostate cancers," Cancer Research, vol. 71, no. 16, pp. 5387-5392, 2011.

[59] M. N. Davies, M. Volta, R. Pidsley et al., "Functional annotation of the human brain methylome identifies tissue-specific epigenetic variation across brain and blood," Genome Biology, vol. 13, no. 6, Article ID R43, 2012.

[60] A. K. Maunakea, R. P. Nagarajan, M. Bilenky et al., "Conserved role of intragenic DNA methylation in regulating alternative promoters," Nature, vol. 466, no. 7303, pp. 253-257, 2010.

[61] S. B. Baylin and P. A. Jones, "A decade of exploring the cancer epigenome-biological and translational implications," Nature Reviews Cancer, vol. 11, no. 10, pp. 726-734, 2011.

[62] Y. A. Medvedeva, M. V. Fridman, N. J. Oparina et al., "Intergenic, gene terminal, and intragenic $\mathrm{CpG}$ islands in the human genome," BMC Genomics, vol. 11, no. 1, article 48, 2010.

[63] M. Gardiner-Garden and M. Frommer, "CpG islands in vertebrate genomes," Journal of Molecular Biology, vol. 196, no. 2, pp. 261-282, 1987.

[64] M. Meyerson, S. Gabriel, and G. Getz, "Advances in understanding cancer genomes through second-generation sequencing," Nature Reviews Genetics, vol. 11, no. 10, pp. 685-696, 2010.

[65] T. Wang, J. Zeng, C. B. Lowe et al., "Species-specific endogenous retroviruses shape the transcriptional network of the human tumor suppressor protein p53," Proceedings of the National
Academy of Sciences of the United States of America, vol. 104, no. 47, pp. 18613-18618, 2007.

[66] G. Bourque, "Transposable elements in gene regulation and in the evolution of vertebrate genomes," Current Opinion in Genetics and Development, vol. 19, no. 6, pp. 607-612, 2009.

[67] S. J. Chanock, T. Manolio, M. Boehnke et al., "Replicating genotype-phenotype associations," Nature, vol. 447, no. 7145, pp. 655-660, 2007. 


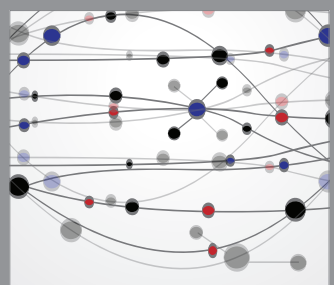

The Scientific World Journal
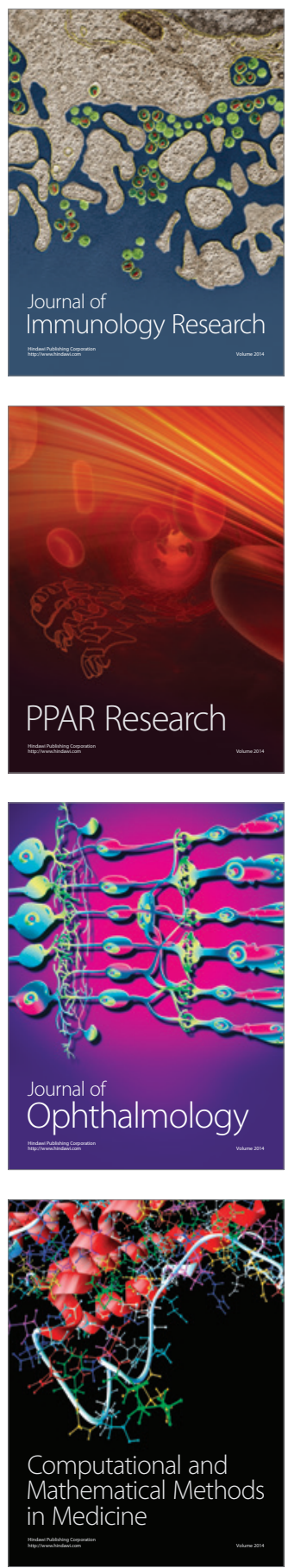

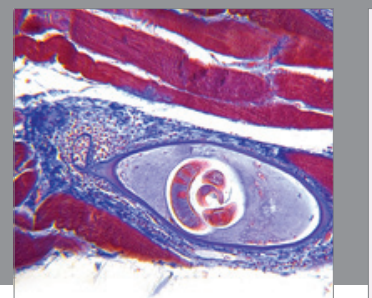

Gastroenterology

Research and Practice
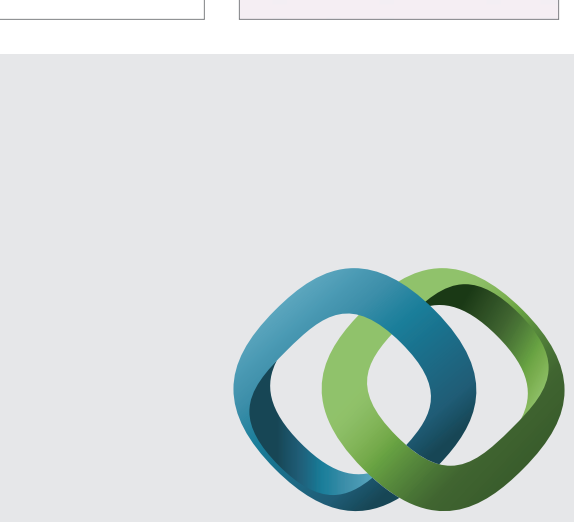

\section{Hindawi}

Submit your manuscripts at

http://www.hindawi.com
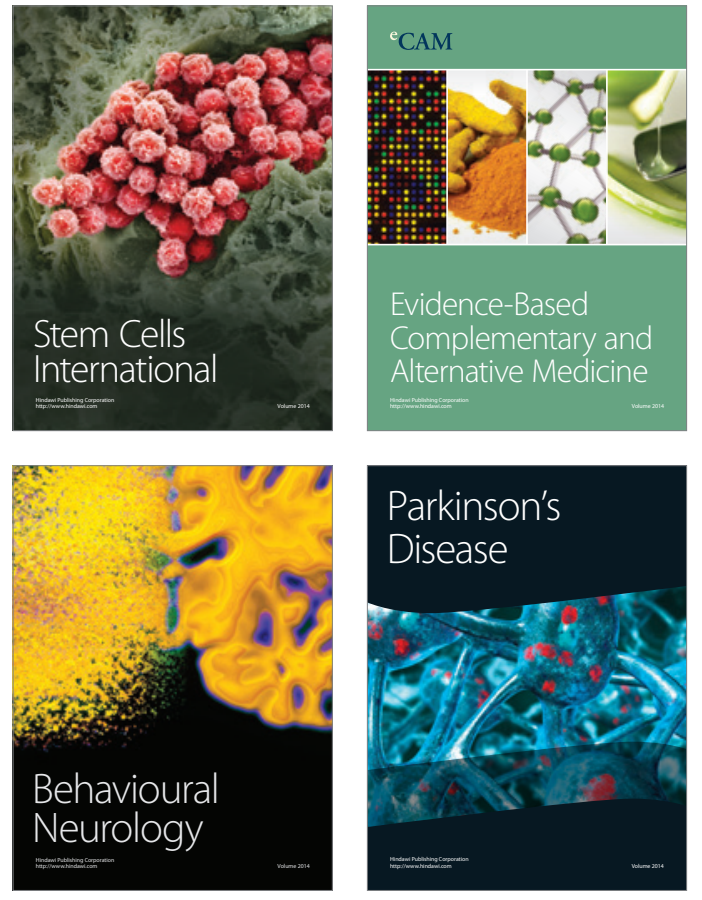
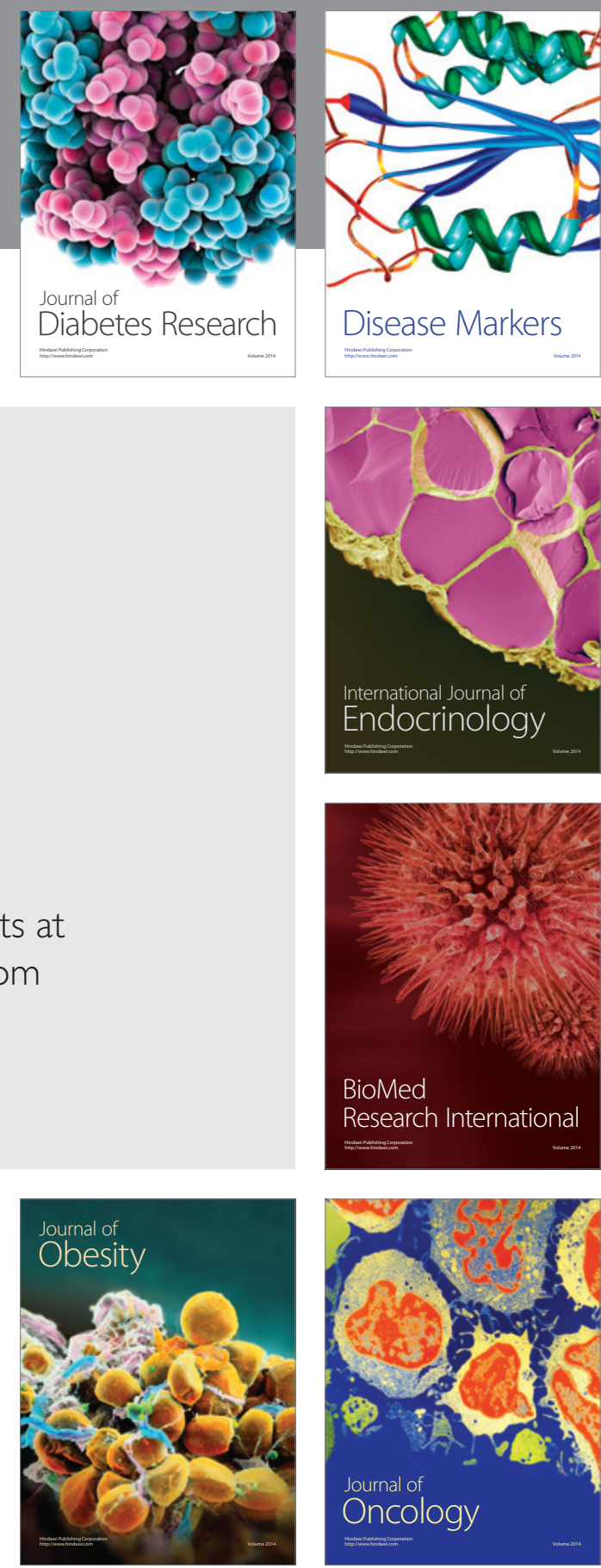

Disease Markers
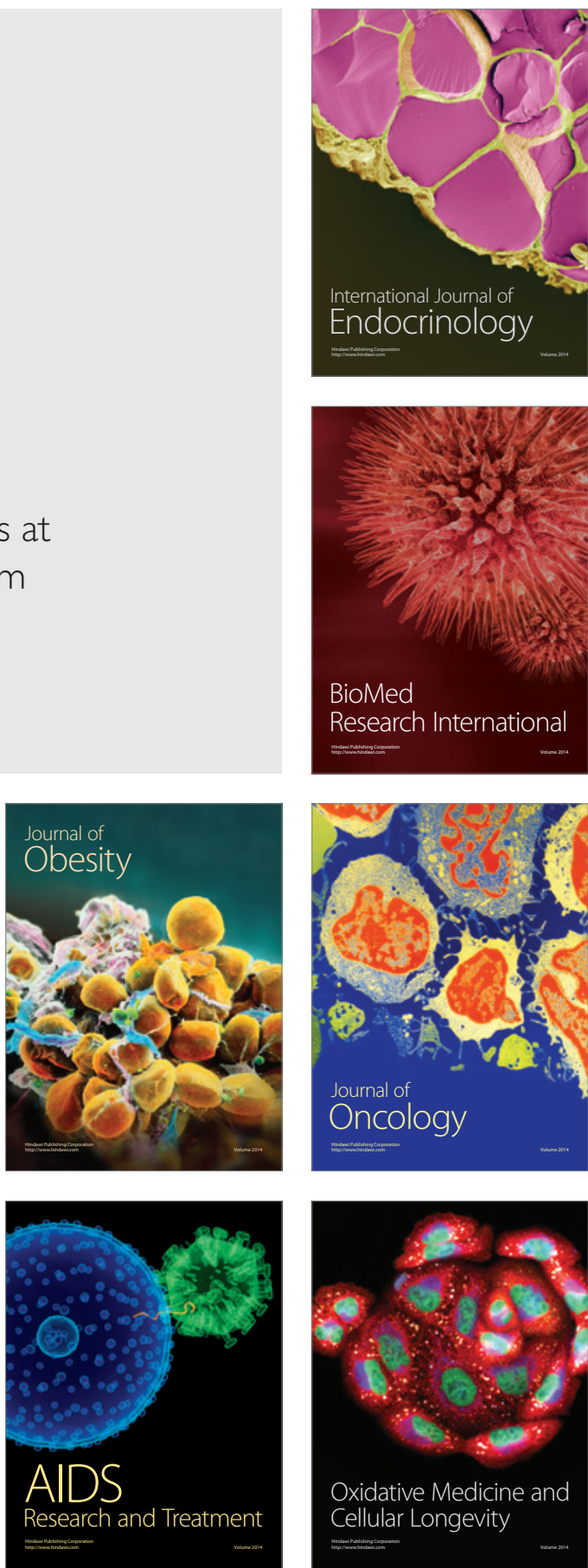